\title{
Misoprostol in the treatment and prevention of nonsteroidal anti-inflammatory drug-induced gastrointestinal mucosal injury
}

NAURANG M AGRAWAL, MD

\begin{abstract}
Three studies are discussed with regard to the efficacy of misoprostol, a synthetic prostaglandin $E_{1}$ analogue, in the treatment and prevention of NSAID-induced gastroduodenal lesions in patients with rheumatoid arthritis and osteoarthritis. In the treatment study, misoprostol was found to be highly effective in healing aspirin-induced gastroduodenal lesions, eg, intramucosal hemorrhage, erosions, and gastric and duodenal ulcers, in patients with theumatoid arthritis continuing NSAID therapy. Treatment successes were reported in $60 \%$ (week 4 ) and $70 \%$ (week 8 ) of patients receiving misoprostol compared with $31 \%$ (week 4 ) and $25 \%$ (week 8 ) of patients receiving placebo $(\mathrm{P}=0.0001$ ). Furthermore, misoprostol did not adversely affect anti-inflammatory and analgesic efficacy of aspirin in rheumatoid arthritis. In one prevention study, misoprostol co-administered with therapeutic doses of NSAIDs, was found to be safe and effective in preventing NSAID-induced gastric ulcers in osteoarthritic patients. At week 12, 94\% of patients on $100 \mu \mathrm{g}$ misoprostol qid were ulcer-free versus $99 \%$ on $200 \mu \mathrm{g}$ misoprostol qid and $78 \%$ on placebo $(\mathrm{P}<0.001)$. In a second prevention study the preliminary analysis of data showed the superior efficacy of misoprostol compared to sucralfate in preventing NSAID-induced gastric ulcers. New findings from research on prostaglandin analogues suggest that they may have therapeutic applications beyond the prevention and treatment of NSAID. induced gastrointestinal mucosal damage. Misoprostol may protect against NSAIDinduced renal dysfunction, may reduce the damage to cartilage that has been associated with some NSAIDs, and is associated with a reduction in the incidence of rejection crises as well as with improvement in renal function in patients undergoing renal transplantation. Can J Gastroenterol 1990;4(3):120-125
\end{abstract}

Key Words: Gastroduodenal lesions, Misoprostol, NSAIDs, Osteoarthritis, Prostaglandin $E_{1}$, Rheumatoid arthritis

Tulane Medical School, New Orleans, Louisiana, USA

Correspondence and reprints: Dr Naurang M Agrawal, Tulane Medical School, Room 7012. 1430 Tulane Avenue, New Orleans, LA 70112, USA. Telephone (504) 588-5329

\begin{abstract}
A SPIRIN AND OTHER NON. steroidal anti-inflammatory drugs (NSAIDs) are highly effective in reducing joint pain and swelling, and are therefore frequently used by physicians worldwide for treating rheumatic diseases. It is generally recognized, however, that these drugs can cause varying degrees of gastroduodenal mucosal damage. With regard to the treatment of NSAID-induced gastric mucosal damage, the synthetic prostaglandins appear to be therapeutically superior over other forms of therapy. Misoprostol is a synthetic prostaglandin $\mathrm{E}_{1}$ analogue with gastric antisecretory (1) and cytoprotective (2) properties. This drug has been shown in many studies to be an effective agent for the prevention of gastric ulcer secondary to NSAIDs as well as for the healing of both gastric and duodenal ulcer when aspirin and NSAIDs are continued.

The following studies provide evidence as to the efficacy of misoprostol in the treatment and prevention of NSAID-induced gastroduodenal injury in patients with rheumatoid arthritis or osteoarthritis.
\end{abstract}




\section{Le misoprostol dans le traitement et la prévention des lésions de la muqueuse gastrique provoquées par les anti-inflam- matoires non stéroïdiens}

RESUME: On rapporte trois études portant sur l'efficacité du misoprostol, analogue synthétique de la prostaglandine $E_{1}$, dans le traitement et la prévention des lésions gastroduodénales induites par les AINS, chez les patients atteints de polyarthrite rhumatoide et d'arthrose. L'étude relative au traitement montre l'efficacité élevée du misoprostol dans la guérison des lésions gastroduodénales provoquées par l'aspirine (p ex, hémorragie de la mugueuse, érosions, ulcères gastriques et duodénaux) chez les patients atteints de polyarthrite rhumatoïde et d'arthrose poursuivant une thérapie par AINS. Les succès du traitement ont été rapportés à $60 \%$ (semaine 4 ) et à $70 \%$ (semaine 8 ) chez les patients recevant du misoprostol, contre $31 \%$ (semaine 4 ) et $25 \%$ (semaine 8 ) chez les patients recevant un placebo $(\mathrm{P}=0,0001)$. De surcroît, le misoprostol n'a pas diminué l'efficacité anti-inflammatoire et analgésique de l'aspirine dans la polyarthrite rhumatoïde. Dans une étude relative à la prévention, l'administration concomitante de misoprostol et de doses thérapeutiques d'AINS s'est avérée sûre et efficace dans la prévention des ulcères gastriques provoquées par les AINS, chez les patients souffrant d'arthrose. A la douzième semaine, $94 \%$ des patients prenant $100 \mu \mathrm{g}$ de misoprostol qid ne présentaient aucun ulcère, contre $99 \%$ à la posologie de $200 \mu \mathrm{g}$ qid, et $78 \%$ chez les patients recevant un placebo $(\mathrm{P}, 001)$. Dans une seconde étude relative à la prévention, l'analyse préliminaire des données démontre l'efficacité supérieure du misoprostol comparé au sucralfate dans la prévention des ulcères gastriques provoqués par les AINS. Les derniers résultats de la recherche sur les analogues de la prostaglandine indiquent que leurs applications thérapeutiques dépassent peut-être la prévention et le traitement des lésions de la muqueuse gastro-intestinale provoquées par les AINS. Le misoprostol est associé à une réduction de l'incidence des épisodes de rejet ainsi qu'à l'amélioration de la fonction rénale chez les receveurs de greffe rénale traités aux stéroïdes et à la cyclosporine.

\section{TREATMENT}

Roth and colleagues (3) conducted a multicentre, double-blind, placebo controlled, randomized study to determine the effects of misoprostol in reducing aspirin-induced gastroduodenal lesions in patients with active rheumatoid arthritis. Since prostaglandins have inflammatory properties, the effect of misoprostol was also evaluated on the antirheumatic activity of aspirin. Patients and methods: Patients included in the study were required to have the following characteristics: definite or classical rheumatoid arthritis as defined by criteria established by the American Rheumatoid Association (currently referred to as the American College of Rheumatology); functional capacity classification of stage I to III; onset of rheumatoid arthritis after age 16.

During the pretreatment phase, all patients received aspirin alone, qid for four weeks, with an average daily dose of $3.9 \mathrm{~g}$. After four weeks of aspirin monotherapy, patients underwent endoscopy for evaluation of gastrointestinal damage. Endoscopic findings were graded according to the criteria listed in Table 1. Those with endoscopic scores of 3 or more qualified for the treatment segment and were randomly assigned to receive eight additional weeks of therapy with a fixed dose of aspirin plus either misoprostol $200 \mu \mathrm{g}$ qid or placebo qid. During this segment of the study, patients were evaluated for rheumatoid arthritis disease activity every two weeks (Table 2) and underwent endoscopy every four weeks.

Three hundred and twenty-six patients with rheumatoid arthritis were entered into the study. After four weeks of aspirin therapy, 270 patients were endoscoped. The remainder were either lost to follow-up or refused endoscopy. Of the patients who underwent endoscopy, 239 had significant gastric mucosal damage; an endoscopic score of 3 to 7 was required to qualify for randomization into the two treatment groups. Thirty-one patients did not have sufficient gastric mucosal injury to qualify

\begin{tabular}{|c|c|}
\hline Score & Description \\
\hline 0 & Normal mucosa \\
\hline 1 & $\begin{array}{l}\text { Slight diffuse mucosa: } \\
\text { hyperemic changes }\end{array}$ \\
\hline 2 & $\begin{array}{l}\text { Single hemorrhagic lesion } \\
\text { or area of marked patchy } \\
\text { erythema }\end{array}$ \\
\hline 3 & $\begin{array}{l}\text { Two to five hemorrhagic } \\
\text { lesions }\end{array}$ \\
\hline 4 & $\begin{array}{l}\text { Six to } 10 \text { hemorrhagic } \\
\text { lesions partially confluent } \\
\text { or connected with areas } \\
\text { of patchy erythema }\end{array}$ \\
\hline 5 & $\begin{array}{l}\text { Large area of confluent } \\
\text { hemorrhagic lesions }\end{array}$ \\
\hline 6 & $\begin{array}{l}\text { Erosions with white bases } \\
\text { surrounded by } \\
\text { erythematous edges }\end{array}$ \\
\hline 7 & Well defined ulcer crater(s) \\
\hline
\end{tabular}

Reproduced with permission from Agrawal NM Dajani EZ. Int J Clin Pharmacol Res. (In press)

for randomization. After eight weeks of treatment, 198 patients were evaluable for efficacy. Nineteen were dropped from the study because of adverse experiences and 22 patients were dropped because of deviation from the protocol or not having endoscopy during the treatment phase.

Of the 19 patients who were withdrawn from the study because of adverse effects, nine $(7.3 \%)$ were in the misoprostol group and $10(8.6 \%)$ were in the placebo group. Six patients in the miso-

\section{TABLE 2}

\section{Assessment of rheumatoid arthritis disease activity}

Joint tenderness

Interference with daily activity

Joint swelling

Grip strength

Functional capacity

Duration of morning stiffness

Pain at rest

Pain at movement

Erythrocyte sedimentation rate

Physician global assessment

Patient global assessment

Reproduced with permission from Agrawai NM Dajani EZ. Int J Clin Pharmacol Res. (In press) 
prostol group had abdominal pain, one had abnormal liver function tests, one suffered dizziness and one had dyspepsia. In the placebo group, two patients had abdominal pain, two gastrointestinal hemorrhage, one was anemic, two had abnormal liver function tests, one suffered chest pain and myalgia and two had dysplasia on gastric mucosal biopsy.

The criteria for treatment success in this study were based on changes in endoscopic score as follows: for patients with pretreatment scores of 7 or 6 , a decrease of at least one grade was required, indicating disappearance of ulcer or erosion; for patients with pretreatment scores of 5,4 , or 3 , a decrease of at least 2 grades was required, indicating significant improvement in mucosal damage.

After four weeks of aspirin alone, prior to randomization, $22 \%$ of patients had ulcers, $50 \%$ had erosions and $18 \%$ had various types of mucosal hemorrhages; only $10 \%$ of the patients did not experience sufficient damage to qualify for randomization. Thus, in this set of patients with rheumatoid arthrit is there is little doubt that chronic, high dose aspirin therapy for relief of the signs and symptoms of rheumatoid arthritis caused significant mucosal damage.

Results and discussion: When the effects of concomitant treatment of aspirin and either misoprostol or placebo on gastric mucosal damage were examined, there were significant differences between the two groups at both four and eight weeks (Figure 1). After four weeks of concomitant treatment, treatment successes were recorded in $69 \%$ of patients receiving misoprostol and $31 \%$ of patients receiving placebo $(P=0.0001)$. After eight weeks, the therapeutic success rate remained constant at $70 \%$ in the misoprostol group, but decreased to $25 \%$ in the placebo group $(\mathrm{P}=0.0001)$.

When the effects on duodenal mucosal injury of combined treatment with aspirin and misoprostol or aspirin and placebo were evaluated (Figure 2), significantly more improvement was noted in duodenal mucosal injury among patients who received misoprostol compared to those who received placebo at week 4 as well as at week $8(81 \%$

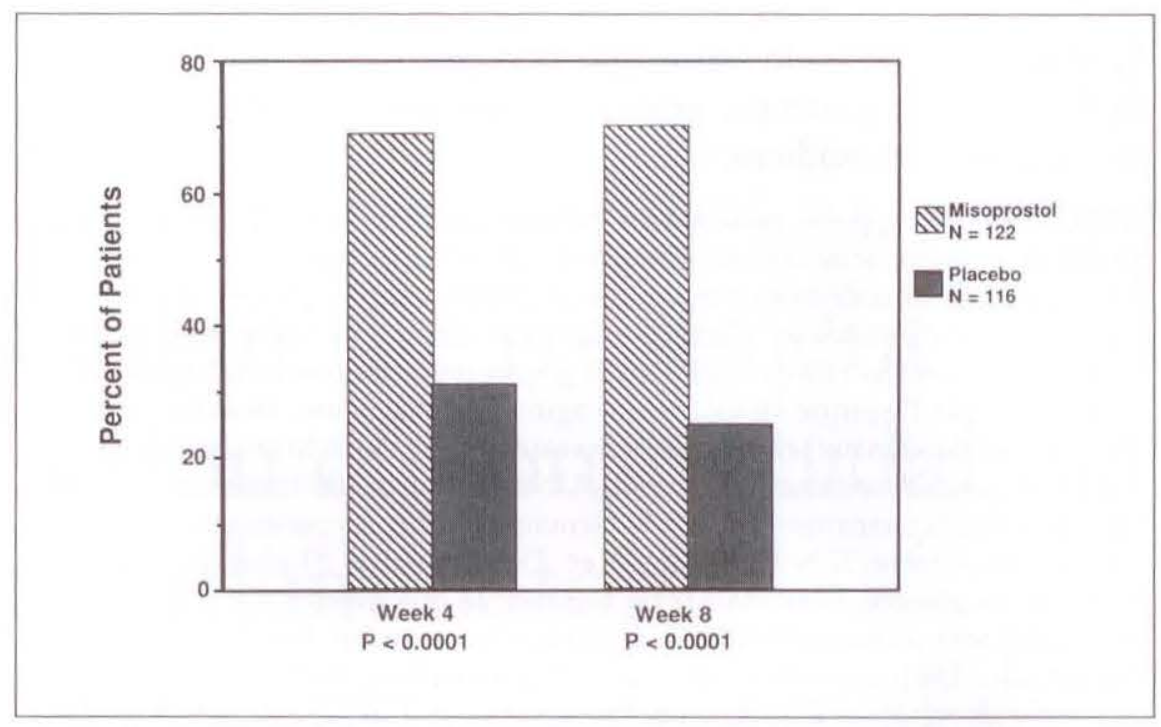

Figure 1) Therapeutic success rates for the gastric mucosa after four and eight weeks of concomitant therapy with aspirin and misoprostol or placebo. (Reproduced with permission from Agrawal NM, Dajani EZ. Int J Clin Pharmacol Res. [In press]) and $86 \%$ compared to $47 \%$ and $53 \%$, respectively). The differences between the two groups were statistically significant at both four weeks $(\mathrm{P}=0.002)$ and eight weeks $(\mathrm{P}=0.001)$.

In this study, 36 patients assigned to the misoprostol group and 34 patients assigned to the placebo group had gastric or duodenal ulcer at randomization. Of particular importance was the presence of on-going aspirin use. After four weeks, $56 \%$ of misoprostol patients with initial gastroduodenal ulcers (Fig- ure 3) versus $24 \%$ of the placebo patients were ulcer-free $(\mathrm{P}=0.0056), 67 \%$ versus $26 \%$ (misoprostol versus placebo) were ulcer-free after eight weeks $(\mathrm{P}=0.0006)$.

No clinically significant differences were found in rheumatoid disease activity between patients receiving misoprostol and placebo. Thus, misoprostol did not interfere with the antirheumatic efficacy of aspirin, but provided significant healing of aspirin-induced mucosal damage.

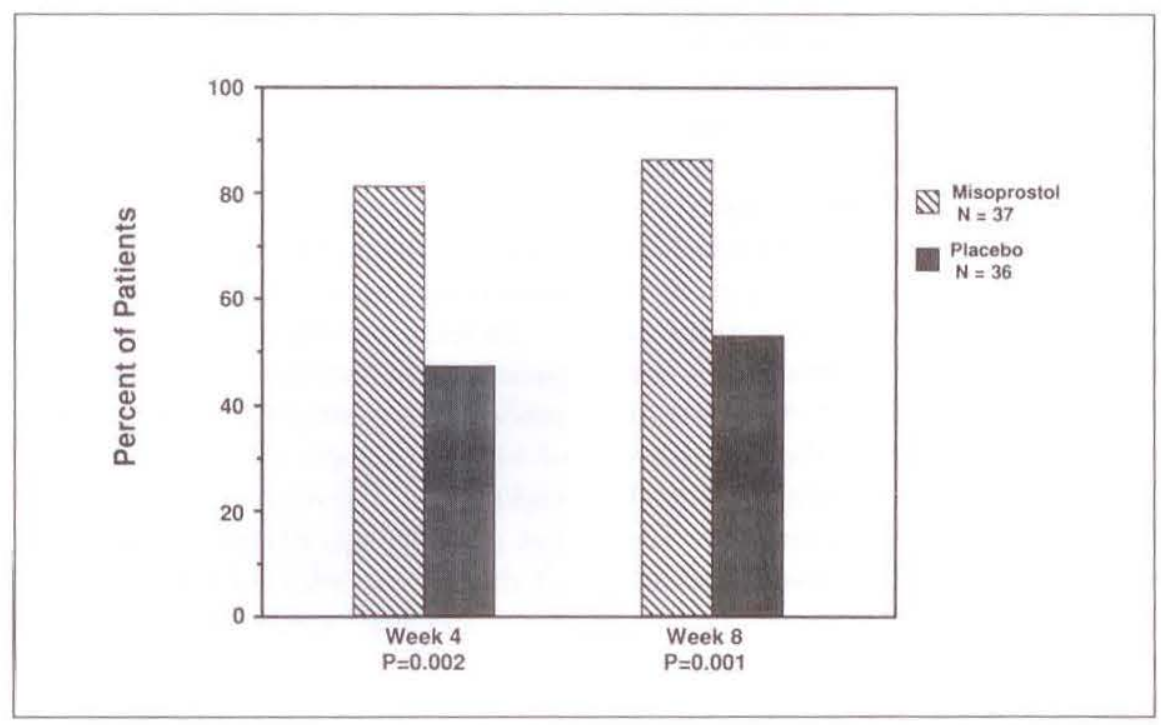

Figure 2) Therapeutic success rates for the duodenal mucosa after four and eight weeks of concomitant therapy with aspirin and misoprostol or placebo. (Reproduced with permission from Agrawal NM, Dajani EZ. Int J Clin Pharmacol Res. [In press]) 


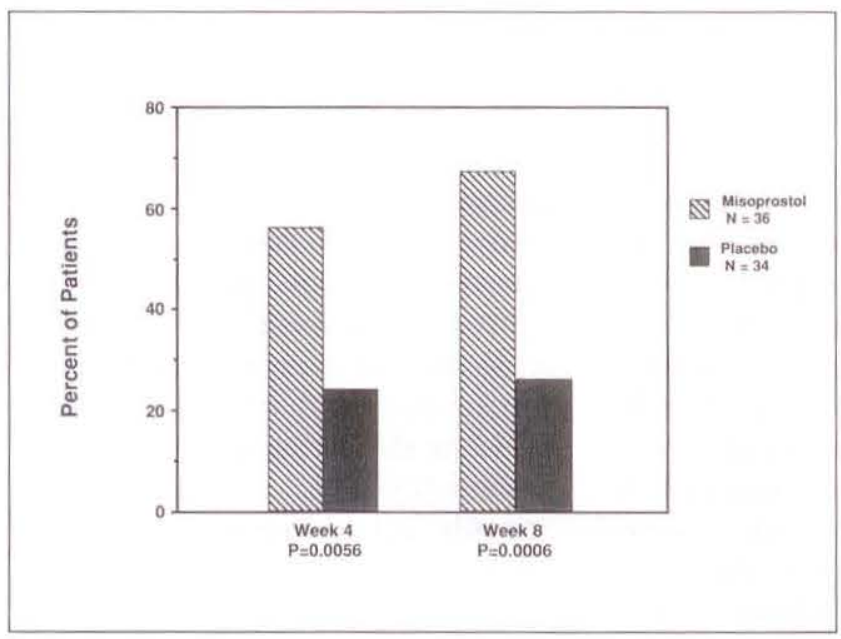

Figure 3) Therapeutic success rates for gastroduodenal ulcers after four and eight weeks of concomitant therapy with aspirin and misoprostol (light columns; $n=36$ ) or placebo (dark columns; $n=34$ ). (Reproduced with permission from Agrawal NM, Dajani EZ. Int J Clin Pharmacol Res. [In press])

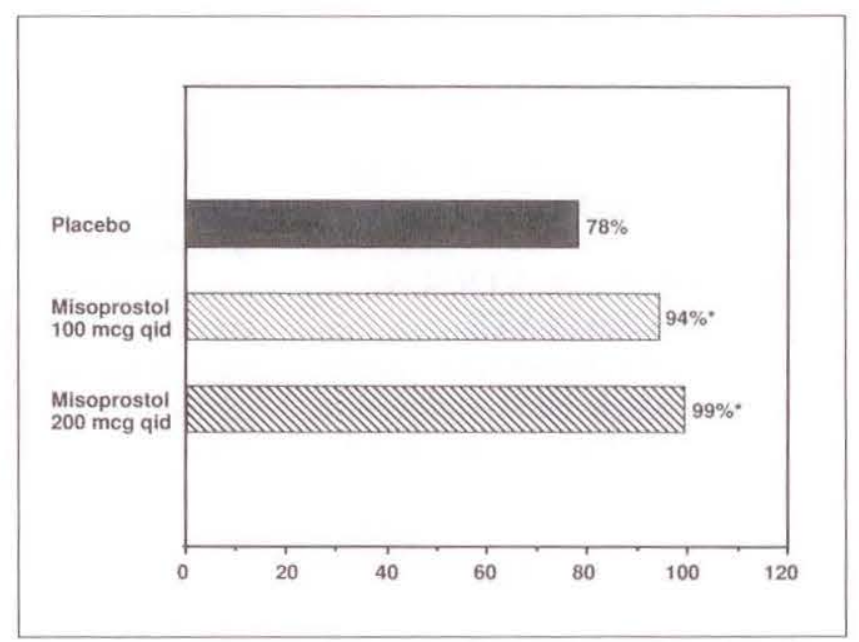

Figure 4) Percentage of patients without ulcers after 12 weeks of co-therapy with NSAIDs. ${ }^{*} P<0.001$. (Reproduced with permission from Agrawal NM, Dajani EZ. Int J Clin Pharmacol Res. [In press])
Examination of the incidence of adverse reactions revealed only one important difference between the two treatment groups. This was the incidence of diarrhea, which was seen in $14 \%$ of the patients who received misoprostol versus $6 \%$ of patients who received placebo. However, in the majority of the patients who experienced diarrhea while receiving misoprostol, this was short lived, mild, and self-limiting. Only $4 \%$ of patients had to be withdrawn from the study as a consequence of diarrhea.

From this study, it can be concluded that misoprostol is effective in healing aspirin-induced gastric and duodenal mucosal damage, is safe, well tolerated and does not interfere with the antirheumatic activity of aspirin.

\section{PREVENTION}

Graham and colleagues (4) conducted a double-blind, placebo controlled study to determine the effectiveness of misoprostol in preventing gastric ulcers and relieving abdominal pain, both induced by NSAID use. The study included 420 patients with osteoarthritis and NSAID-associated abdominal pain. NSAID therapy consisted of ibuprofen, piroxicam or naproxen. Demographic characteristics relating to age, sex, and duration of osteoarthritis were similar in all patients. Only patients with normal endoscopic findings or erosions and intramucosal hemorrhages were randomized into the three treatment groups: $100 \mu \mathrm{g}$ misoprostol qid, $200 \mu \mathrm{g}$ misoprostol qid or placebo qid for a subsequent 12 weeks while patients continued to take their NSAIDs. Endoscopic examination was conducted at four-week intervals for the following 12 weeks.

The number of patients in each treatment group who developed gastric ulcers during the three month follow-up period was the principal measurement. Gastric ulcers were defined as circumscribed breaks in the gastric mucosa of $0.3 \mathrm{~cm}$ in diameter or greater. NSAID. associated abdominal pain was assessed independently, based on the patient's daily rating, as recorded on a diary card, and the investigators' monthly ratings of abdominal pain. Patients who were found to have an ulcer at the time of the screening endoscopy, totalling $25 \%$, were included in a separate study in which they were treated with $200 \mu \mathrm{g}$ misoprostol qid for eight weeks. If the ulcers healed, these patients could be included in the prevention study.

Of the patients who received misoprostol $100 \mu \mathrm{g}$ qid while continuing to receive NSAID, 94\% were ulcer-free at the end of 12 weeks (Figure 4). Of those who concurrently received misoprostol $200 \mu \mathrm{g}$ qid and NSAID therapy for os- teoarthritis, $99 \%$ were ulcer-free at the end of 12 weeks. Only $78 \%$ of the placebo-treated patients were ulcer-free. The difference found between each of the misoprostol groups as compared to the placebo group was statistically significant $(P<0.001)$. The significant difference between the frequency of gastric ulcers held up well when the comparison was restricted to all protocol defined ulcers and to those of $0.5 \mathrm{~cm}$ or greater $(12.3,4.2$ and $0.7 \%$ for placebo, $100 \mu \mathrm{g}$ misoprostol and $200 \mu \mathrm{g}$ misoprostol, respectively).

By the end of 12 weeks, abdominal pain was relieved in $57 \%$ of patients in the placebo group compared to $70 \%$ in each misoprostol group. This difference, however, was not statistically significant. It should also be noted that all patients at the time of entry had abdominal pain.

The most common side effects were abdominal pain, diarrhea, dyspepsia, flatulence and nausea. All of these side effects were equally divided among the three treatment groups, with the exception of $2.8 \%$ of patients in the $100 \mu \mathrm{g}$ misoprostol group and $6.4 \%$ in the 200 $\mu \mathrm{g}$ misoprostol group who were withdrawn from the study because of diarrhea.

From this study, it can be concluded that misoprostol, at doses of 100 and $200 \mu \mathrm{g}$ qid, given with therapeutic 
doses of NSAIDs, is safe and effective in preventing NSAID-induced gastric ulcers in patients with osteoarthritis and does not increase abdominal pain or other gastrointestinal symptoms.

\section{MISOPROSTOL VERSUS SUCRALFATE}

Agrawal and colleagues, in a recent randomized, single-blind multicentre trial (unpublished data), compared the efficacy and safety of misoprostol and sulcralfate (a drug used but not proven effective in the treatment of gastroduodenal ulcer) in the prevention of NSAID-induced gastric ulcer in osteoarthritic patients.

Two hundred and sixty-eight ulcerfree patients on chronic NSAID therapy were randomized to receive either misoprostol (Cytotec; Searle) $200 \mu \mathrm{g}$ qid or sucralfate $1 \mathrm{~g}$ qid for three months. Efficacy was based on monthly endoscopy results. A prophylaxis failure was defined as any ulcer $0.3 \mathrm{~cm}$ in diameter or larger.

Preliminary analysis of the results showed misoprostol to be significantly more effective than sucralfate in the prevention of NSAID-induced gastric ulcers.

\section{MISOPROSTOL BEYOND THE GASTROINTESTINAL TRACT}

New findings from research on prostaglandin analogues suggest that they may have therapeutic applications beyond the prevention and treatment of NSAID drug-induced gastrointestinal mucosal damage.

Anti-inflammatory effect: Studies in animals and humans have demonstrated that prostaglandins may have anti-inflammatory properties (5). For example, misoprostol recently has been shown to reduce inflammation in a rat paw model (data on file; Searle, Skokie, Illinois) and, under certain circumstances, adds to the effects of diclofenac, a well established anti-inflammatory compound. This is contrary to the widely held belief that prostaglandins are causative agents of inflammation.

NSAID-induced renal dysfunction: Research indicates that misoprostol may protect against NSAID-induced renal dysfunction, an adverse effect re- ported with NSAID use which occurs in association with reduced prostaglandin synthesis in the kidney.

In an open label, crossover study (unpublished data), two groups of elderly women (age 50 or greater) were entered to determine if misoprostol could prevent NSAID (indomethacin)-induced renal impairment. Either normotensive female or hypertensive female patients received, in random sequence, indomethacin $25 \mathrm{mg}$ qid, misoprostol $200 \mu \mathrm{g}$ qid, and a combination of the two. Kidney function was evaluated by measuring glomerular filtration rate, renal plasma flow and sodium intake. In $50 \%$ of both the normotensive and hypertensive groups, indomethacin caused a reduction in glomerular filtration rate and renal plasma flow (more than $5 \%$ ). When misoprostol was administered with indomethacin to this same group of patients, two-thirds of the patients who had previously shown a reduction in glomerular filtration rate and renal plasma flow were shown not to have a reduction.

These results suggest that NSAIDs can cause a reduction in renal function in a sizable proportion of patients, and that co-administration of misoprostol may offer protection against this NSAID-induced renal injury.

NSAID-related cartilage degradation: In recent years there has been growing concern that certain NSAIDs may have a deleterious effect on cartilage (6-11). Preliminary data suggest that misoprostol may reduce the damage to cartilage that has been associated with some NSAIDs both in vivo and in vitro. While the mechanism of action that leads to cartilage damage is not well understood, prolonged secretion of cytokines is a suspected cause of cartilage degradation.

Generally, prostaglandins regulate cytokine levels by preventing excessive secretion. However, as NSAIDs inhibit $\mathrm{PGE}_{2}$, the end result may be that cytokines continue to be secreted and ultimately are a factor in cartilage damage. It is suggested that misoprostol's value as adjunctive prostaglandin therapy may result from its ability to reduce the secretion of cytokines.

A preliminary study in pig cartilage was designed to assess the effects of misoprostol in modulating damage (unpublished data). Cartilage treated with the NSAID naproxen showed damage whereas cartilage treated with only misoprostol showed no effect. However, coadministration of misoprostol with naproxen inhibited cartilage degradation. This study lends further support to the idea that misoprostol may modulate the damaging effects caused by some NSAIDs.

Steroids and cyclosporine: It is well known that cyclosporine can cause renal damage and is associated with impaired prostaglandin output. In this regard, researchers have hypothesized that misoprostol could play a protective role as a prostaglandin supplement (12). Clinical investigation among renal transplant patients receiving steroids and cyclosporine revealed that administration of misoprostol is associated with a reduction in the incidence of rejection crises and with improved renal function.

In a study of 77 kidney transplant recipients, 65 of whom completed the study, patients received either cyclosporine and steroids or the combination with the addition of misoprostol (13). Kidney function as measured by serum creatinine and urinary creatinine clearance improved by 20 to $25 \%$ in the patients receiving misoprostol. Furthermore, the number of transplant rejection cases was dramatically reduced by about two-thirds within the first month of treatment, a time when the majority of crises occur. Such effects were largely maintained over the three-month study. Laboratory mixed lymphocyte response testing also confirmed the immunosuppressive activity of steroids, cyclosporine and misoprostol when given together.

The implication is that misoprostol actually may increase the disease-modifying effect of steroids and/or cyclosporine in the treatment of theumatoid arthritis and therefore merits further examination.

\section{CONCLUSIONS}

Several conclusions can be drawn from the above evidence. First, co-administration of misoprostol is highly effective in healing aspirin-induced 
gastroduodenal lesions, eg, intramucosal hemorrhage, erosions, gastric and duodenal ulcers, in patients with rheumatoid arthritis. Secondly, misoprostol does not adversely affect anti-inflammatory and analgesic efficacy of aspirin in rheumatoid arthritis. Thirdly, misoprostol, given at doses of 100 and 200 $\mu \mathrm{g}$ qid and co-administered with thera-

\section{REFERENCES}

1. Dajani EZ. Perspective on the gastric antisecretory effects of misoprostol in man. Prostaglandins 1987;33(Suppl):68.

2. Dajani EZ. Mucosal protective activities of misoprostol in man: An overview. In: Bianchi G, Pooro RR, Dajani EZ, eds. Gastrointestinal Cytoprotection by Prostaglandins: Focus on Misoprostol. Verona: Cortina International, 1987;21-31.

3. Roth S, Agrawal N, Mahowald M, et al. Misoprostol heals gastroduodenal injury in patients with rheumatoid arthritis receiving aspirin. Arch Intern Med 1989;149:775-9.

4. Graham DY, Agrawal NM, Roth SH. Prevention of NSAID-induced gastric ulcer with misoprostol: Multicentre, double-blind, placebo-controlled trial. Lancet 1988;ii:1277-80.

5. Zurier RB, Hoffstein S, Weissman G. peutic doses of NSAIDs, is safe and effective in preventing NSAID-induced gastric ulcers in osteoarthritis patients. Fourthly, on preliminary analysis misoprostol appears to be significantly superior to sucralfate in preventing NSAIDinduced gastric ulcers. Finally, new findings from research on prostaglandin analogues suggest that they

Suppression of acute and chronic inflammation in adrénalectomized rats by pharmacologic amounts of prostaglandins. Arthritis Rheum 1973;16:606.

6. Coke H. Long-term indomethacin therapy of coxartherosis. Ann Rheum Dis 1967;26:346-7.

7. Arora JS, Maudsley RH. Induced arthropathy of hips. Proc Roy Soc Med 1968;61:669.

8. Ronningen $\mathrm{H}$, Langeland $\mathrm{M}$. Indomethacin treatment in osteoarthritis of the hip joint. Does the treatment interfere with the natural cause of the disease? Acta Orthop Scand 1979;50:169-74.

9. Newman NM, Ling RSM. Acetabular bone destruction related to nonsteroidal anti-inflammatory drugs. Lancet $1985 ; \mathrm{ii}: 11-3$.

10. Doherty M, Holt M, MacMillan P, Watt I, Dieppe PA. A reappraisal of may have therapeutic applications beyond the prevention and treatment of NSAID-induced gastrointestinal mucosal damage. Misoprostol is associated with a reduction in the incidence of rejection crises, as well as with improvement in renal function in patients undergoing renal transplantation, receiving steroids and cyclosporine.

'analgesic hip'. Ann Rheum Dis 1986;45:272-6.

11. Doherty M. 'Chondroprotection' by non-steroidal anti-inflammatory drugs. Ann Rheum Dis 1989;48:619. 21.

12. Mozes M, et al. Misoprostol improves renal function and reduces the frequency of acute rejection in cyclosporine-treated renal transplant recipients. Kidney Int 1988;35:520. (Abst)

13. Moran M, Mozes MF, Maddux MS, et al. Prostaglandin supplementation with misoprostol in cyclosporinetreated renal transplant recipients. (In press)

14. Agrawal NM, Dajani EZ. Treatment and prevention of nonsteroidal antiinflammatory drug induced gastrointestinal mucosal injury. Int J Clin Pharmacol Res. (In press) 


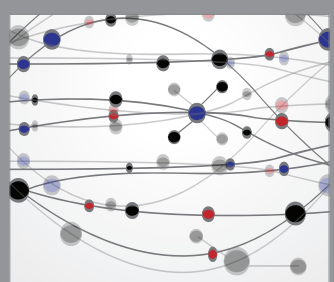

The Scientific World Journal
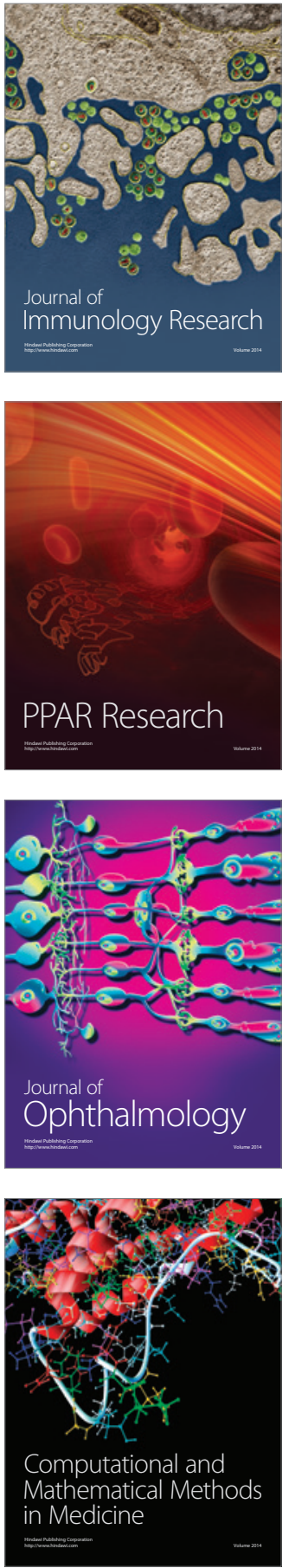

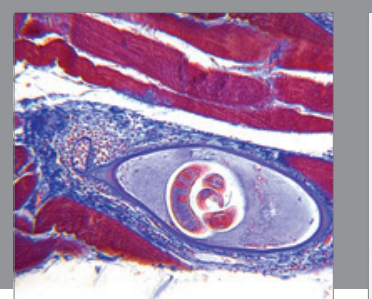

Gastroenterology Research and Practice

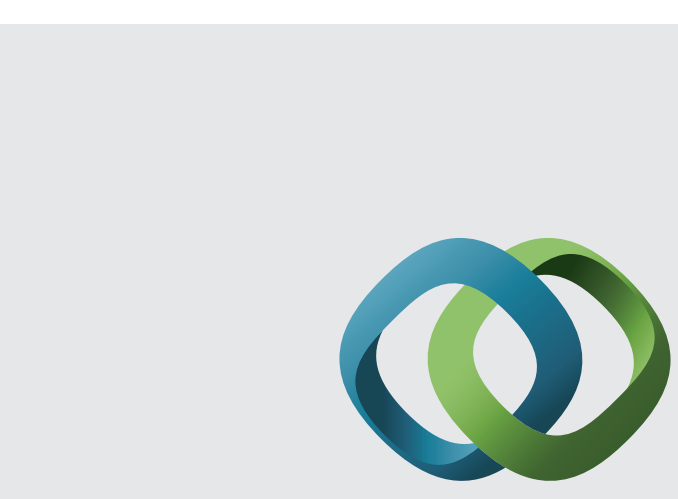

\section{Hindawi}

Submit your manuscripts at

http://www.hindawi.com
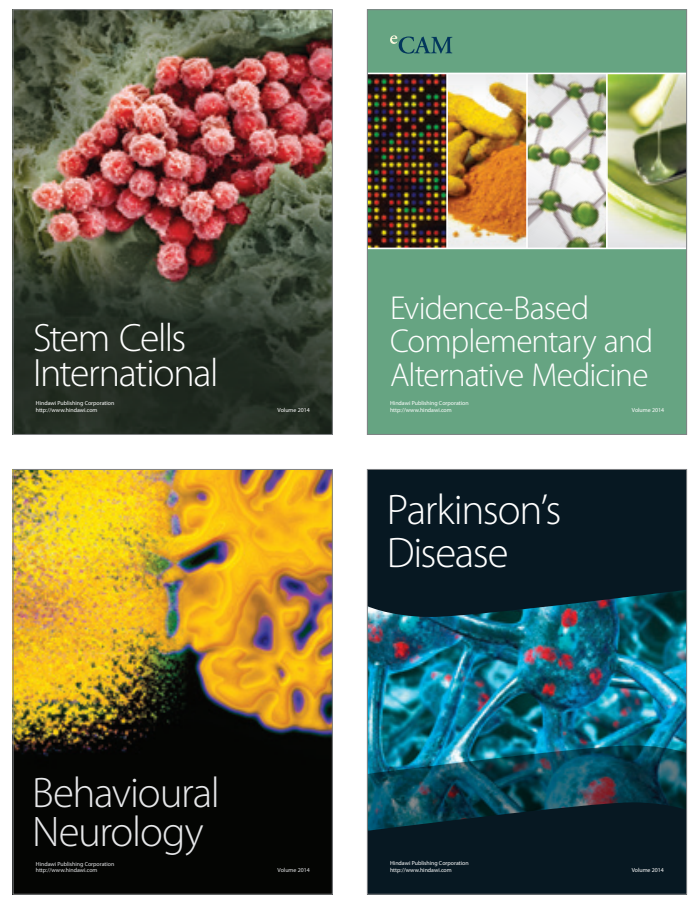
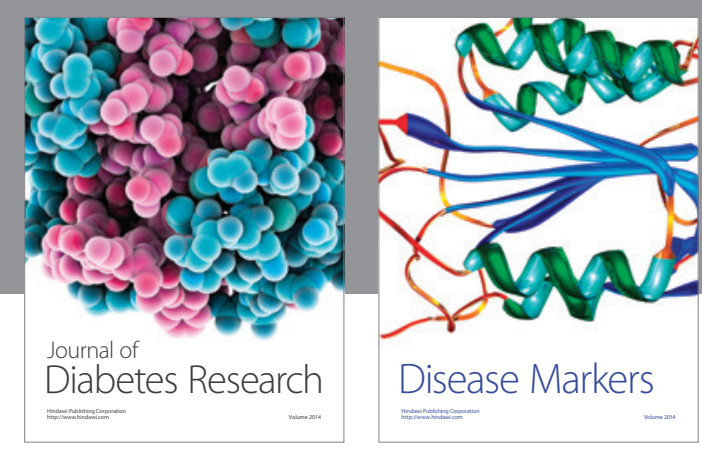

Disease Markers
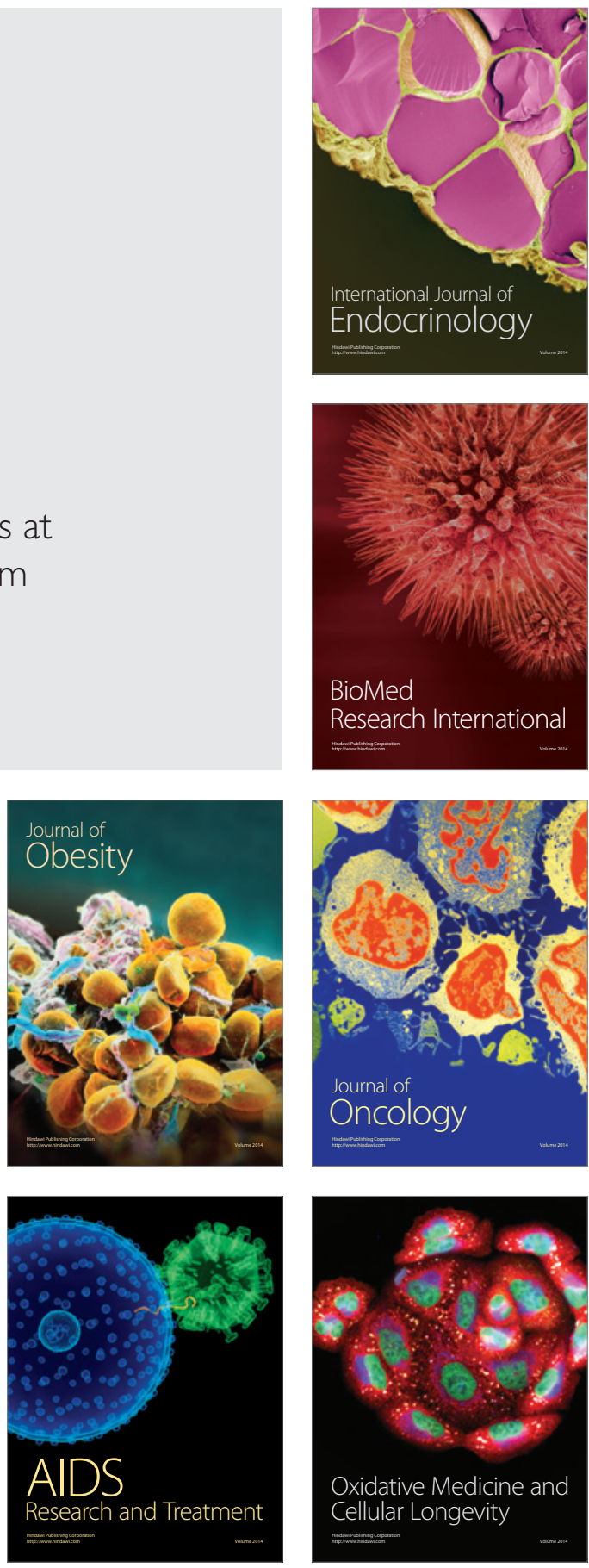